\title{
Short-term outcomes predictors of hip arthroscopy in male patients aged 50 or younger
}

\author{
Jesús Mas Martínez ${ }^{* 1}$, Javier Sanz-Reig ${ }^{1}$, David Bustamante Suárez de Puga ${ }^{1}$, Manuel Morales Santias ${ }^{1}$, \\ Enrique Martínez Giménez ${ }^{1}$, and Carmen María Verdú Román ${ }^{1}$ \\ ${ }^{1}$ Hip Unit, Department of Orthopedic Surgery, Clinical Vistahermosa, Alicante, Spain.
}

Received: April 05, 2017; Accepted: May 26, 2017; Published: June 30, 2017

*Corresponding author: Dr. Jesus Más Martínez, Hip Unit, Department of Orthopedic Surgery, Clinical Vistahermosa,Av de Dénia, 103

03015 Alicante, Spain;E-mail:Jmas@traumavist.com

\section{Abstract}

Introduction: The aim of this study was to identify patient-related outcomes predictors of treatment failure following Hip Arthroscopy, in male patients aged 50 years or younger.

Material and Methods: Prospective study of 150 male patients aged 50 or younger undergoing hip arthroscopybetween January 2009 and April 2014. Modified Harris Hip Score, HOS and IHOT questionnaires were used for clinical assessment. Radiological evaluation was made for joint space, alpha angle and Tönnis grade

Results: The mean age of the patients was 38.0 years. The mean postoperative follow-up was 44.5 months. There was a significantly improvement in the mean score in the clinical questionnaires $(p<0.05)$. Thirteen patients $(8.7 \%)$ required second-look arthroscopy or conversion to total hip replacement. Survivorship for revision as end-point was $87.4 \%$. In univariate analysis, age, preoperative $\mathrm{mHHS}$, joint space and Tönnis grade were potential predictors of revision. However, multivariate regression analysis revealed that significant independent predictor was only joint space lower than $2 \mathrm{~mm}$.

Conclusions: Pain and function enhanced significantly after hip arthroscopy. But we found in male patients aged 50 years or younger with joint space lower than $2 \mathrm{~mm}$ higher unsuccessful clinical result and the need for revision surgery.

Keywords: Hip; Arthroscopy; Middle Aged; Treatment Outcome.

\section{Introduction}

TStudies of arthroscopic treatment in Femoroace tabular impingement (FAI) show improvement in pain, activities of daily living and sports [1-3]. Currently, the numbers of HA continues to grow in young active population. Philippon reported that in patients aged 50 years or older with joint space lower than 2 $\mathrm{mm}$ and low preoperative mHHS, early conversion to total hip replacement was seen[4].But, are these variables useful in younger patients?

This study of a consecutive series of male patients aged 50 years or younger had the purpose to investigate, which factor is the main contributor to pain and decreased function after HA. We hypothesized that patients with $2 \mathrm{~mm}$ of joint space or less, and low preoperative mhhs, would have unsuccessful clinical results and the need for revision surgery.

\section{Material and Methods}

From January 2009 we have been filling, in our database, patients treated with HA. We consulted this database for male patients 50 years of age and younger, with diagnosis of FAI and secondary labral tears, complete clinical assessment scores and radiographic measurements and underwent at least a 2-year post hip arthroscopy follow-up. The exclusion criterion was diagnosis of hip dysplasia, Perches disease, previous hip surgery and were aged under 18.

The study was approved by our Institutional Review Board (IRB) and an informed consent was obtained from all individual participants included in the study.

All operations were performed under spinal anaesthesia in an operating room. All patients included in this study underwent HA by the same surgeons (J.M.M., J.S.R.). Patients were positioned supine on a modified traction table and subjected to traction to distract the operative hip. Two standard arthroscopy portals were used, the anterolateral portal and the midanterior portal. Initially we systematically evaluated the labrum and ace tabular cartilage. The severity of chondral delaminating was evaluated using the Multicenter Arthroscopic Hip Outcome Research Network (MAHORN) classification[3]. We divided into two groups as Mahorn O, I and II (mild group), and Mahorn III, IV and $\mathrm{V}$ (severe group). To report the geographic location of intraarticular injuries we used the Ilizariturri method [5]. Femoral osteoplasty and resection of pincer lesion was performed using a 5.5-mm burr. The capsule was not repaired. The portals were closed and a sterile dressing was applied.

All patients were treated with the same postoperative pain management and specific rehabilitation protocol after HA. Patients were discharged 24 hours after HA. They were placed on crutches for 3 weeks with foot flat partial weight bearing. Passive hip rotation was restricted for 4 weeks.

Clinical and radiographic evaluations were performed pre-and postoperatively at 3, 6, 12 months, and then annually. All clinical evaluation forms were completed at each visit by two experienced surgeons (D.V.S.P., M.M.S) who was not involved in the surgeries. Clinical assessment was performed through the modified Harris Hip Score[6] (mhhs), a self-administered Hip Outcome 
Score[7] (HOS) questionnaire, with activity of daily living (ADL) and sports subscale (SSS) translated into Spanish and validated[8], and a self- administered short version of the International Hip Outcome Tool [9] (ihot-12).

True anteroposterior plain pelvic and Dunn lateral radiographs were performed pre- and postoperatively. Radiographic evidence of pincer-type consisted in the presence of relative ace tabular retroversion on the anteroposterior plain pelvic radiograph, as indicated by a cross-over sign and prominent ischial spine sign. Cam impingement was defined as the loss of femoral head-neck offset on the Dunn lateral radiograph [10]. All radiographs were graded using the Tönnis grading system[11] and joint space at the middle of the source was measured on the anteroposterior plain pelvic radiograph[12]. The alpha angle was also measured using the Dunn lateral radiograph [12].All postoperative radiographs were analyzed by two independent experienced surgeons (E.M.G., C.M.V.R.) who did not know the names of the patients or their clinical evaluations.

Non-contrast magnetic resonance imaging (MRI) was required before surgery to detect the presence of a vascular necrosis, labral tear or cartilage injury.

In order to determine the effectiveness of Hip arthroscopy in this group of patients, failure was defined as mHHS $<80$ points (poor or fair result)[13], undergoing a second-look arthroscopy or a conversion to total hip replacement (THR).

Statistical analyses were conducted with SPSS software v. 20.0 (SPSS Inc., Chicago, USA).The statistical significance was considered for $\mathrm{p}$ values less than 0.05 . Normal distribution was determined by the Kolmogorov-Smirnov test. For comparison of continuous variables, we used the Student t-test or non-parametric Mann-Whitney U-test for 2 variables and 1-way analysis. For categorical variables the chi-square test, the Fisher exact test or the Mantel-Haenszel was used. For assessing associations between continuous variables the Pearson's r correlation coefficient was calculated. Multivariate analysis was performed to analyze the strongest independent predictors of clinical failure or revision surgery. Odds ratios and the 95\% confidence intervals were presented. The Kaplan-Meier test was used for cumulative survival analysis.

\section{Results}

Between January 2009 and March 2014, 266 patients underwent HA. One hundred and fifty met the inclusion criteria and were included in the study. No loss of follow-up was considered. reports demographic and radiological factors of the patients. (Table 1)

Hip arthroscopy showed cam lesion in 140 hips (93.3\%) and pincer lesion in 73 hips (48.6\%). All together, FAI was cam type in 77 hips (51.3\%), mixed type in 63 hips (42\%), and pincer type in 10 hips (6.8\%). There were labral tears in 90 hips (60\%), degenerative labrum lesion in 36 hips (24\%), and no labrum lesion in 24 hips (16\%). The majority (82.1\%) occurred in the antero superior quadrant (zone 2 and 3). There was no relation between labral pathology and duration of symptoms prior to surgery, alpha angle, joint space, or Tönnis grade ( $p>0.05)$.
Table:1 Demographic and radiological factors (Mean values + SD)

\begin{tabular}{|c|c|}
\hline Variable & \\
\hline Age (years) & $38.0 \pm 8.3$ \\
\hline Age 41 - 50 years & $66(44 \%)$ \\
\hline $\begin{array}{c}\text { Symptoms prior to surgical intervention } \\
\text { (months) }\end{array}$ & $22.3 \pm 11.2$ \\
\hline Laterality (right) & $76(50.7 \%)$ \\
\hline Alpha angle (degrees) & $64.8 \pm 8.7$ \\
\hline Joint space (mm) & $4.5 . \pm 1.2$ \\
\hline Joint space < 2 mm & $9(6.0 \%)$ \\
\hline Tönnis 0-1 & $117(78 \%)$ \\
\hline Tönnis 2-3 & $33 \%)$ \\
\hline
\end{tabular}

Chondral damage was detected in 113 (75.3\%) hips. According to the Mahorn classification there were 37 hips (24.7\%) type 0 , 9 hips (6\%) type I, 14 hips (9.3\%) type II, 25 hips (16.7\%) type III, 22 hips (14.7\%) type IV, and 43 hips (28.7\%) type V. They were located in zone 2 and 3 in 78.4\%. In 60 hips (40\%) chondral damage was graded as mild and in 90 hips $(60 \%)$ as severe. Severe chondral damage was significant related with longer duration of symptoms prior to surgery $(\mathrm{p}=0.03)$, greater alpha angle $(\mathrm{p}=0.02)$, joint space less than $2 \mathrm{~mm}(\mathrm{p}=0.04)$, and Tönnis grade $2-3(\mathrm{p}=0.001)$.

Femoral osteoplasty was performed in 77 hips (51.3.\%) alone, femoral osteoplasty with rim reduction in 63 hips (42\%), and rim reduction alone in 10 hips (6.8\%). For labral pathology, there were 90 hips $(60 \%)$ that underwent labral repair, and 36 hips $(24 \%)$ that had partial labral debridement using thermal ablation and/or shaving techniques. Labral repair was made with multiple suture anchors (Push lock® 2,9 mm. Anthrax inc. Naples, Florida). An average of 2.6 suture anchors was used per repair (range, 1 to 4 ). For chondral lesion, in 43 hips (28.7\%) with Mahorn grade $\mathrm{V}$ chondral defects were treated with micro fracture. In 70 hips (46.6\%) with Mahorn grade I to IV chondral defects were treated with debridement chondroplasty. There was no association between the condition of the articular cartilage and the labrum $(\mathrm{p}=0.08)$.

The mean postoperative follow-up was 44.5 months (range 34 to 57; SD 3.4).

The mean change in patient-reported outcome scores was compared between preoperative and last follow-up data. Radio logically, there were statistical differences between the preoperative mean alpha angle and its value at last follow-up. The mean joint space was similar (Table 2). 
Table 2: Preoperative and last follow-up patient-reported outcome scores and diological outcomes (Mean values $+\mathrm{SD}$ )

\begin{tabular}{|c|c|c|c|}
\hline Variable & Preop & Last follow-up & $\mathbf{p}$ \\
\hline mHHS & $72.9 \pm 13.3$ & $89.7 \pm 14.5$ & 0.02 \\
\hline HOS-ADL & $63.9 \pm 18.9$ & $85.9 \pm 24.7$ & 0.01 \\
\hline HOS-SSS & $38.1 \pm 25.2$ & $71.6 \pm 38.5$ & 0.001 \\
\hline IHOT-12 & $37.1 \pm 20.8$ & $63.9 \pm 39.8$ & 0.001 \\
\hline $\begin{array}{c}\text { Alpha angle } \\
\text { (degrees) }\end{array}$ & $63.3 \pm 8.7$ & $44.1 \pm 7.0$ & 0.001 \\
\hline $\begin{array}{c}\text { Joint space } \\
\text { (mm) }\end{array}$ & $4.1 . \pm 1.1$ & $4.4 . \pm 1.3$ & 0.86 \\
\hline $\begin{array}{l}\text { mHHS, Modified Harris Hip Score; HOS-ADL, Hip Outcome Score-Activ- } \\
\text { ities of Daily Living; HOS-SSS, Hip Outcome Score-Sports Specific Sub- } \\
\text { scale; IHOT, International Hip Outcome Tool. }\end{array}$ \\
\hline
\end{tabular}

Patients without labrum and chondral damage had the greatest improvement. The differences were statistically significant in
HOS and ihot-12 for the labrum damage and in mHHS, HOS and ihot-12 for the chondral damage (Table 3). There were no statistically significant differences in hip function regarding to the type of impingement, labral repair or debridement, chondral micro fracture or chondroplasty $(\mathrm{p}>0.05)$.

Thirteen patients $(8.7 \%)$ had mHHS lower than 80 points, and all required second-look arthroscopy or conversion to THR. Eight of them, 3 Tönnis 0, 3 Tönnis 1, and 2 Tönnis 2, and joint space greater than $2 \mathrm{~mm}$, were treated with second-look arthroscopy undergoing reshaping of cam deformity because of an inadequate resection at the first operation. The mean time from HA to second-look was 13 months (range, 12 to 17 months). The other five patients, 2 Tönnis 2, and 3 Tönnis 3 , and joint space less than $2 \mathrm{~mm}$, were treated with conversion to THR. The mean time from HA to THR was 20 months (range, 18 to 25 months). There was a significant difference between this group and the group that not required revision surgery in age, preoperative mHHS, joint space, joint space of $2 \mathrm{~mm}$ or less, and Tönnis grade (Table 4). In multivariate regression analysis, only joint space of $2 \mathrm{~mm}$ or less was identified as independent predictor of revision surgery (Table 5).

Table 3: Patient-related outcome scores related to labral injury or chondral damage (Mean values + SD)

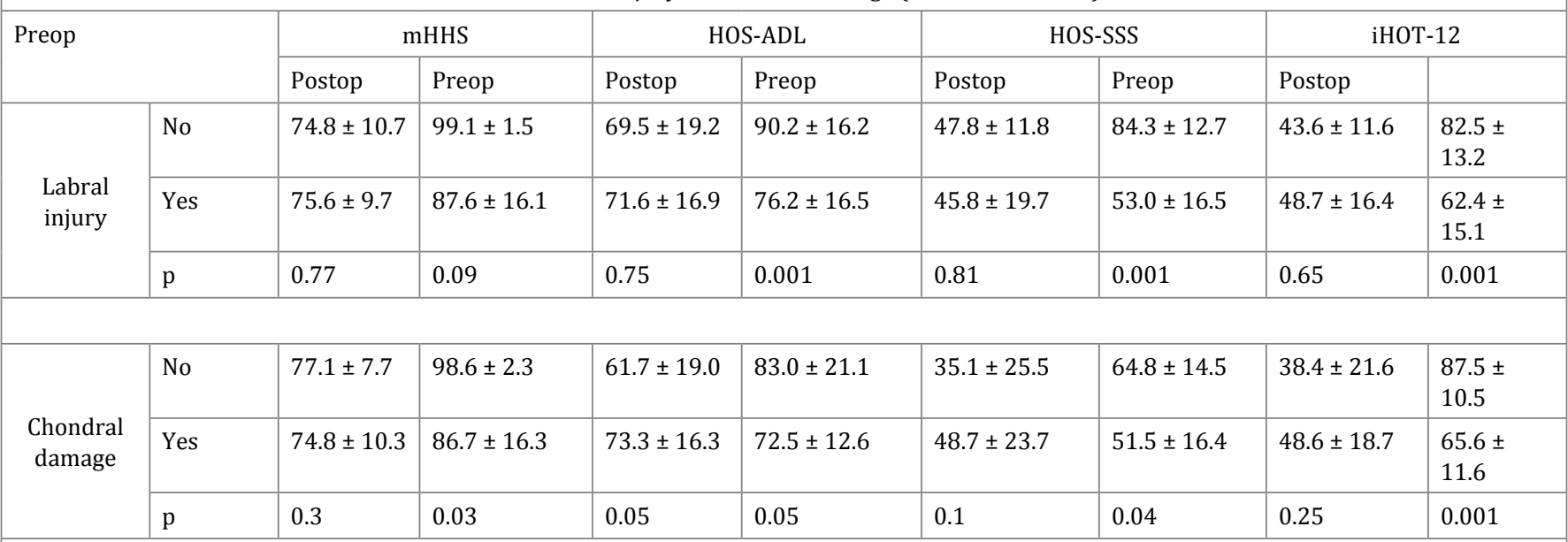

mHHS: modified Harris Hip Score; HOS-ADL: hip outcome score for activities of daily living; HOS-SSS: hip outcome score for sports; iHOT-12: international hip outcome tool

Table 4: Comparative analysis of patients who required and did not required revision surgery (Mean values + SD)

\begin{tabular}{|c|c|c|c|c|c|}
\hline Variable & Revisión surgery & $\begin{array}{l}\text { Not revision } \\
\text { surgery }\end{array}$ & $\mathbf{p}$ & $\begin{array}{l}\text { Adjusted odds } \\
\text { ratio }\end{array}$ & 95\% CI \\
\hline Age & $44.2 \pm 3.4$ & $37.4 \pm 8.3$ & 0.001 & & \\
\hline Age $41-50$ & 10 & 55 & \multirow{2}{*}{0.01} & \multirow{2}{*}{4.9} & \multirow{2}{*}{$1.3-18.8$} \\
\hline Age $<40$ & 3 & 82 & & & \\
\hline $\begin{array}{c}\text { Symptoms prior to } \\
\text { HA (months) }\end{array}$ & $21.2 \pm 15.6$ & $22.4 \pm 20.0$ & 0.8 & & \\
\hline Preoperative mHHS & $71.6 \pm 13.2$ & $77.0 \pm 8.9$ & 0.05 & & \\
\hline Joint space & $3.2 \pm 1.7$ & $4.6 \pm 1.1$ & 0.1 & & \\
\hline Joint space $>2 \mathrm{~mm}$ & 8 & 133 & \multirow{2}{*}{0.001} & \multirow{2}{*}{11.34} & \multirow{2}{*}{$3.47-37.05$} \\
\hline Joint space $\leq 2 \mathrm{~mm}$ & 5 & 4 & & & \\
\hline
\end{tabular}

Citation:Jesús Mas Martínez, Javier Sanz-Reig, David Bustamante Suárez de Puga,et.al. (2017) Short-term outcomes predictors of hip arthroscopy in male patients aged 50 or younger. J Excer Sports Orthop 4(2):1-6. 


\begin{tabular}{|c|c|c|c|c|}
\hline Tönnis 0-1 & 6 & 111 & 0.01 & 2.61 \\
\hline Tönnis 2-3 & 7 & 26 & 0.34 & \\
\hline Labral injury yes & 13 & 113 & & \\
\hline Labral injury no & 0 & 24 & 0.76 & \\
\hline $\begin{array}{c}\text { Chondral damage } \\
\text { Mahorn grade 0-1-2 }\end{array}$ & 4 & 56 & & \\
\hline $\begin{array}{c}\text { Chondral damage } \\
\text { Mahorn grade 3-4-5 }\end{array}$ & 9 & 81 & & \\
\hline
\end{tabular}

Table 5: Multivariate analysis: second-look arthroscopy or conversion to total hip replacement.

\begin{tabular}{|c|c|c|c|c|c|}
\hline Variable & B-coefficient & SE & $\mathbf{p}$ & Exp B & CI95\% Exp B \\
\hline Joint space $\leq 2 \mathrm{~mm}$ & $-2,599$ & 1,01 & 0,02 & 0,02 & $0,01-0,39$ \\
\hline Preoperative mHHS & 0,02 & 0,03 & 0,48 & 0,48 & $0,95-1,09$ \\
\hline
\end{tabular}

Using Kaplan-Meier test with revision as end-point, the survivorship at 2 years follow-up was $87.4 \%$ (95\% CI, 76.6\%96.2\%) (Fig 1).At 2 years follow-up, patients with joint space greater than $2 \mathrm{~mm}$ had a survivorship of $96 \%$ whereas those with $2 \mathrm{~mm}$ or less has a survivorship of $42 \%$ ( $\mathrm{p}<0.001$ ) (Fig 2).

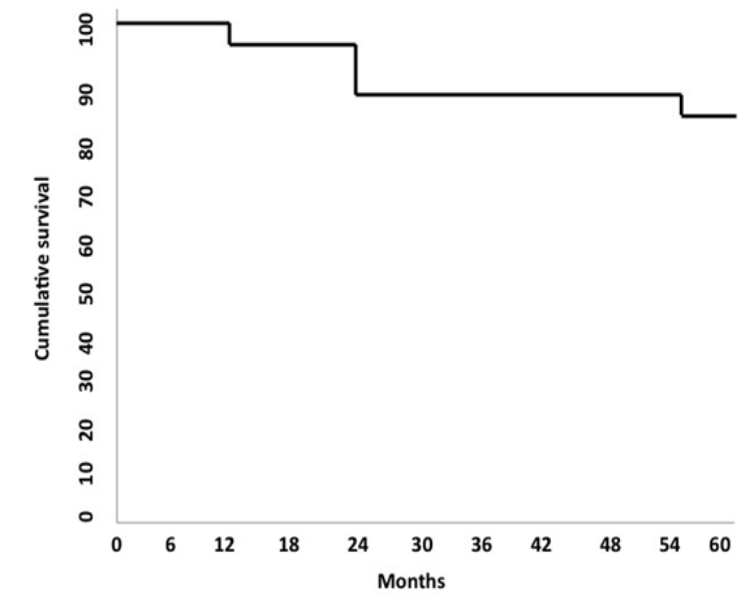

Figure 1: Survivorship curve for all patients. Survivors were operationally defined as those who did not require revision surgery or had not clinical failure. Each time the graph steps down it represents a decrease in survivorship of patients. The graph shows that most of the losses occurred within the first 24 months.

\section{Discussion}

The most important finding in the present study was that male patients aged 50 years or younger withpreoperative joint space lower than $2 \mathrm{~mm}$ following hawere more likely to undergo a revision surgery.

Previous studies reported that the presence of arthritis at the time of surgery resulted in uniformly poor results $[14,15]$. Philippon informed that Tönnis grade was accurate in $65 \%$ of patients to predict conversion to total hip replacement or non-

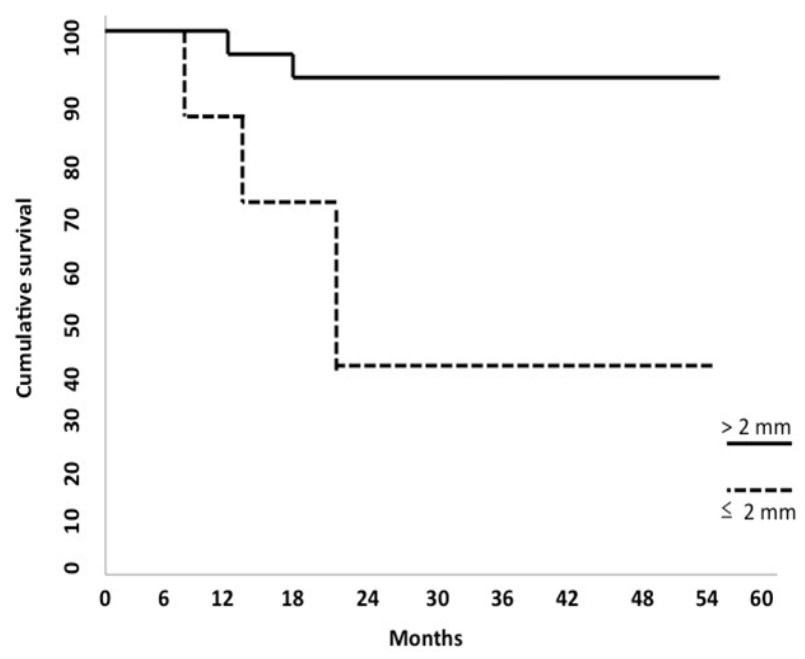

Figure 2: Survivorship curve with patients divided by joint space. Patients with $2 \mathrm{~mm}$ of joint space or less show only $42 \%$ survivorship at 2 years.

total hip replacement at 3 years after $\mathrm{HA}$, but in patients older than 50[16]. And two studies with Tönnis grade 2 or greater used as exclusion criteria found that no patients required subsequent THR $[17,18]$.

Joint space narrowing before arthroscopy was another predictor of clinical failure [15]. Philipp on reported that in patients 50 years aged or older with joint space of $2 \mathrm{~mm}$ or less, early conversion to THR was seen after HA at 3 years' follow-up [4]. We confirm in our study that in patients under 50 , joint space of $2 \mathrm{~mm}$ or less was also related to revision surgery in the short follow-up period.

Preoperative mHHS was also reported as a predictor of clinical failure in patients 50 years aged or older [4]. In our study, patients that required revision surgery had preoperative mHHS score lower than patients that not required revision surgery, and 
this difference was significant. But preoperative mHHS score was not a predictor of revision surgery in patients 50 years aged or younger.

A cartilage lesion at the time of hip arthroscopy is related to clinical assessment in several studies. Streich reported that with respect to the presence of an intra operative articular cartilage defect, it became clear that in subjects with softening of the cartilage there was a significant improvement in the clinical assessment, whereas patients with structural damage showed a tendency to remain at the same level of clinical symptoms or even became worse at 2 years' follow-up [19]. Mc McCarthy [20] and Byrd [21]confirmed these results at 10 years' follow-up and indicated the presence and severity of arthritis or chondral degradation as predictors of worse questionnaire scores. Our results showed that patients with longer duration of symptoms prior to surgery, greater alpha angle, joint space narrowing, joint space of $2 \mathrm{~mm}$ or less than $2 \mathrm{~mm}$ and Tönnis graded 2-3 are more likely to have chondral damage. Outcomes were similar for patients treated with chondral micro fracture or chondroplasty, but these results were lower than in patients without chondral pathology in our clinical assessment tools.

The ace tabular labrum provides stability to distraction forces through the suction effect of the hip fluid seal. Cadaveric studies have demonstrated that partial labral resection significantly decreased the distractive strength of the hip fluid seal and increase the contact pressure on the cartilage [22]. It seems to have better results in hip functional outcomes labral repair instead of labral resection or debridement [23]. But, other studies reported good outcomes with resection at short [24] and long follow-up [25]in patients without arthritis. In our study, labral pathology had no relation to duration of symptoms prior to surgery, alpha angle, joint space or Tönnis grade. And the objective and subjective outcomes were lower in patients with labral pathology. But with respect to patients treated with labral repair or labral debridement, these outcomes were similar.

Our study has several limitations. First, the lack of a control group and short-term follow-up. Second, our sample size was relatively small but the study was adequately powered to detect clinically relevant differences. Third, the size of the cartilage lesions was not recorded, a factor that could affect our results. However, it also has several strengths. First, this is a single-surgeon series. Second, we have used a standardized prospectively collected data, with different tools for assessing clinical results after hip arthroscopy. Third, we have no follow-up losses.

\section{Conclusions}

Based on our short-term results, there is a moderate evidence that preoperative joint space of $2 \mathrm{~mm}$ or lesswas the most important factor of revision surgery or clinical failure after HA in male patients younger than 50 years old.

\section{References}

1. Griffiths EJ, Khanduja V. Hip arthroscopy: evolution, current practice and future developments. Int Orthop. 2012;36(6):1115-1121. Doi: 10.1007/s00264-011-1459-4
2. Ayeni OR, Levy BA, Musahl V, Safran MR . Current state-of-the-art of hip arthroscopy. Knee Surg Sports Traumatol Arthrosc. 2014;22:711713. Doi: doi:10.1007/s00167-014-2866-z

3. Safran MR, Hariri S. Hip arthroscopy assessments tools and outcomes. Oper Tech Orthop. 2010;20(4):264-277. Doi: 10.1053/j. oto.2010.09.014

4. Philippon MJ, Schroder ESBG, Briggs KK. Hip arthroscopy for femoroacetabular impingement in patients aged 50 years or older. Arthroscopy. 2012;28(1):59-65. Doi: 10.1016/j.arthro.2011.07.004

5. Ilizaliturri VM, Byrd JW, Sampson TG, Guanche CA, Philippon MJ, Kelly BT, et al. A geographic zone method to describe intra-articular pathology in hip arthroscopy: cadaveric study and preliminary report. Arthroscopy. 2008;24(5):534-539. Doi: 10.1016/j.arthro.2007

6. Byrd JW, Jones KS. Prospective analysis of hip arthroscopy with 2-year follow-up. Arthroscopy. 2000;16(6):578-587. Doi: 10.1053/ jars. 2000.7683

7. Martin RL, Philippon MJ. Evidence of validity for the hip outcome score in hip arthroscopy. Arthroscopy. 2007;23(8):822-826. Doi: 10.1016/j. arthro.2007.02.004

8. Seijas R, Sallent A, Ruiz-Iban MA, Ares O, Cuellar R, Muriel A, et al. Validation of the Spanish version of the Hip Outcome Score: a multicenter study. Health Qual Life Outcomes. 2014;12:70. Doi: 10.1186/14777525-12-70.

9. Griffin DR, Parsons N, Mohtadi NG, Safran MR, et al. Multicenter Arthroscopy of the Hip Outcomes Research N. A short version of the International Hip Outcome Tool (iHOT-12) for use in routine clinical practice. Arthroscopy. 2012;28(5):611-616.

10. Bedi A, Kelly BT. Femoroacetabular impingement. J Bone Joint Surg Am. 2013;95(1):82-92. Doi: 10.2106/JBJS.K.01219

11. Tonnis D. Normal values of the hip joint for the evaluation of X-rays in children and adults. Clinical Orthop Relat Res. 1976;119:39-47.

12. Philippon MJ, Briggs KK, Yen YM, Kuppersmith DA. Outcomes following hip arthroscopy for femoroacetabular impingement with associated chondrolabral dysfunction: minimum two-year follow-up. J Bone Joint Surg. 2009;91:16-23. Doi: 10.1302/0301-620X.91B1.21329

13. Marchetti P, Binazzi R, Vaccari V, Girolami M, Morici F, Impallomeni $\mathrm{C}$, et al. Long-term results with cementless Fitek (or Fitmore) cups. J Arthroplasty. 2005;20(6):730-737. Doi: 10.1016/j. arth.2004.11.019

14. Byrd JW, Jones KS. Hip arthroscopy for labral pathology: prospective analysis with 10-year follow-up. Arthroscopy. 2009;25(4):365-368. Doi: 10.1016/j.arthro.2009.02.001

15. Meftah M, Rodriguez JA, Panagopoulos G, Alexiades MM. Long-term results of arthroscopic labral debridement: predictors of outcomes. Orthopedics. 2011;34(10):e588-592. Doi: 10.3928/0147744720110826-04

16. Philippon MJ, Briggs KK, Carlisle JC, Diana CP . Joint space predicts THA after hip arthroscopy in patients 50 years and older. Clinical Orthop Relat Res. 2013;471(8):2492-2496. Doi: 10.1007/s11999-0122779-4

17. Schilders E, Dimitrakopoulou A, Bismil Q, Marchant P, Cooke C. Arthroscopic treatment of labral tears in femoroacetabular impingement: a comparative study of refixation and resection with a minimum two-year follow-up. J Bone Joint Surg . 2011;93(8):1027-1032. Doi: 


\subsection{2/0301-620X.93B8.26065}

18.Palmer DH, Ganesh V, Comfort T, Tatman P. Midterm outcomes in patients with cam femoroace tabular impingement treated arthroscopically. Arthroscopy. 2012;28(11):1671-1681. Doi: 10.1016/j.arthro.2012.04.154.

19. Streich NA, Gotterbarm T, Barie A, Schmitt H. Prognostic value of chondral defects on the outcome after arthroscopic treatment of acetabular labral tears. Knee Surg Sports Traumatol Arthrosc. 2009;17(10):12571263. Doi: $10.1007 / \mathrm{s} 00167-009-0833-x$

20. McCarthy JC, Jarrett BT, Ojeifo O, Lee JA, Bragdon CR. What factors influence long-term survivorship after hip arthroscopy?. Clinical Orthop Relat Res. 2011;469(2):362-371. Doi: 10.1007/s11999-010-1559-2

21. Byrd JW, Jones KS. Prospective analysis of hip arthroscopy with 10year followup. ClinOrthop Relat Res. 2010;468(3):741-746. Doi: 10.1007/s11999-009-0841-7

22. Nepple JJ, Philippon MJ, Campbell KJ,et al.The hip fluid seal--Part II: The effect of an acetabular labral tear, repair, resection, and reconstruction on hip stability to distraction. Knee Surg Sports Traumatol Arthrosc. 2014;22(4):730-736. Doi: 10.1007/s00167-014-2875-y
23. Krych AJ, Thompson M, Knutson Z,Scoon J, Coleman SH. Arthroscopic labral repair versus selective labral debridement in female patients with femoroacetabular impingement: a prospective randomized study. Arthroscopy. 2013;29(1):46-53. Doi: 10.1016/j.arthro.2012.07.011

24. Larson CM, Giveans MR, Stone RM. Arthroscopic debridement versus refixation of the acetabular labrum associated with femoroacetabular impingement: mean 3.5-year follow-up. Am J Sports Med. 2015;40(5):1015-1021. Doi: 10.1177/0363546511434578

25. Dippmann C, Thorborg K, Kraemer Oet al. Hip arthroscopy with labral repair for femoroacetabular impingement: short-term outcomes. Knee Surg Sports Traumatol Arthrosc. 2014;22(4):744-749. Doi: 10.1007/ s00167-014-2885-9

26. Chow RM, Owens CJ, Krych AJ, Bruce AL. Arthroscopic labral repair in the treatment of femoroacetabular impingement. Arthrosc Tech. 2013;2(4):e333-e336. Doi: 10.1016/j.eats.2013.04.009 